WellBeing International

WBI Studies Repository

1986

\title{
A Case Against Animal Rights
}

Jan Narveson

University of Waterloo

Follow this and additional works at: https://www.wellbeingintlstudiesrepository.org/acwp_awap

Part of the Animal Studies Commons, Ethics and Political Philosophy Commons, and the Politics and Social Change Commons

\section{Recommended Citation}

Narveson, J. (1986). A case against animal rights. In M.W. Fox \& L.D. Mickley (Eds.), Advances in animal welfare science 1986/87 (pp. 191-204). Washington, DC: The Humane Society of the United States.

This material is brought to you for free and open access by WellBeing International. It has been accepted for inclusion by an authorized administrator of the WBI Studies Repository. For more information, please contact wbisr-info@wellbeingintl.org.

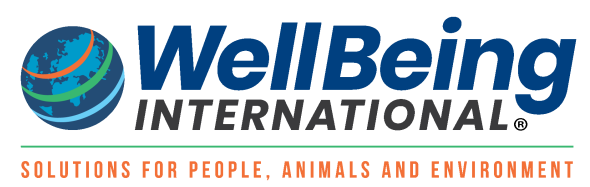




\section{A CASE AGAINST ANIMAK RIGHTS ${ }^{\overline{1}}$}

\section{Jan Narveson ${ }^{2}$}

\section{Introduction}

Down through the past decade and more, no philosophical writer has taken a greater interest in the issues of how we ought to act in relation to animals, nor pressed more strongly the case for according them rights, than has Tom Regan, in many articles, reviews, and exchanges at scholarly conferences and in print. It is a pleasure to join him on this symposium, to explore this interesting and important set of issues.

The importance of the issues is plain enough when we consider the recommendations to which Regan's important book, The Case for Animal Rights (1983) leads up: no animal food in our diets, virtually no use at all of animals for experimental purposes, and more. Few of us would be unaffected by so sweeping a set of strictures. And I know of no better, more philosophically powerful defense of animal rights than Tom Regan's work. It certainly behooves us, then, to follow his arguments with care, to appreciate the challenge of his position, and to provide a satisfactory alternative that gives us, if I may put it that way, a better shake. But there is another reason, as I have said before (Narveson 1977, 1980) : The issue of animal rights is one of the watersheds of moral philosophy. If we are indeed to leave ourselves in anything like the position we presently are inclined assume in relation to animals, an alternation in our understanding of the subject of a rather radical kind, may be in order.

To present all this to you in the time available for this talk is no easy matter. I shall have to be rather skeletal at points, and beg your indulgence if I have gone too far-in either direction!

I shall begin by outlining, as fairly as I can, Regan's view of the matter, and then sketch my alternative. Regan has in fact criticized certain aspects of my position at some length in his book. My replies to those criticisms will be largely implicit here, and I will not dwell on them when outlining his view. 


\section{Regan's Case for Animal Rights}

The first three chapters of The Case for Animal Rights argue for the intermediate conclusion, that considerations of welfare, of well- or ill-being, do literally apply to animals. Animals do actually have a welfare or illfare that we can either cater to or ignore. It is interesting that some philosophers in the past have actually denied this claim. Ren \pm Descartes comes foremost to mind, of course. So it is perhaps in order for me to point out that I accept this thesis without reservation. Animals surely do feel pain, have desires, perhaps emotions, and in some rudimentary sense, thoughts.

Regan, however, goes further than most of us would be inclined to on this important point. For example, he insists that animals have "concepts," and indeed that they have "perception, memory, desire, belief, self-consciousness, intention, a sense of the future-these are among the leading attributes of the mental life of normal mammalian animals aged one or more" (p. 81-all otherwise unattributed references are page references to The Case for Animal Rights). Obviously, we must wonder whether this hasn't been overstated. Most of us have had pets at one time or another and are familiar with the range of behavior on the basis of which Regan makes these strong attributions. To most of us, it will seem not plausible to assert that animals have all of these capacities without severe qualification. In particular, we would be inclined to point to the evidence concerning linguistic behavior as an indication that the mental life of animals is pretty thin stuff compared to that of normal humans. As Regan is aware, recent work on the linguistic capabilities of chimpanzees, the most promising of land-based mammals for these purposes, points to the conclusion that chimpanzees "do not have the ability for language acquisition equal to that of young children" (14). Regan was only concerned to explore this aspect of animal attainments as a test for their possession of consciousness. I accept the view that you can have consciousness without knowing any language at all. But linguistic ability is surely evidence of mental complexity, while the inability to acquire language strongly suggests lack of intellectual ability. And it seems that even very retarded human beings, evidently, are very far in advance of even very bright animals in this regard.

The problem with chimpanzees is not that they don't happen to have acquired such fluency despite their cognitive capacity for acquiring it: It is that they lack that capacity, so far as all current evidence indicates. Most of us would think that this is not a fact to be sneezed at. Of course we might be all wrong about this. But Regan's assessment of the facts here suggests that in his view, higher mental attainment is really irrelevant to the question of whether a being deserves moral consideration. And this seems to me, and I am sure to most people, very disputable indeed. Animals are conscious, indeed: but maybe being conscious isn't all that counts.

There are, of course, other extremely impressive animal skills one can point to. The singular homing abilities of some species, for instance, the incredible mechanisms for self-defense or attack, the astonishing (in human 
terms) capacity for self-sacrifice displayed by ants and bees, and so on. All these are certainly enough to intrigue even the most minimally curious among us. But do they provide support for the view that these beings have moral rights?

Interestingly enough, such attributes of animals have no obvious role to play in Regan's case at all. He is very concerned to show that animals have welfare, that they suffer and they enjoy, that they do indeed have lives to live and lose. But why, we may ask, should we be impressed by that? What we want to know is why these things matter: specifically, why they matter enough to give us good reason to refrain from the many activities in which we make use of animals to their detriment, e.g., by eating them or experimenting with them or wearing their fur.

In a crucial chapter (Ch. 4, "Ethical Thinking and Theory"), Regan articulates his methodology in thinking about these issues. A number of criteria are laid down for making an "ideal moral judgment," and more for appraising proposed moral principles, most of them uncontroversial. But I want to have a closer look at two which loom very large in his arguments: (1) impartiality and (2) "conformity to our intuitions."

Impartiality is something moral philosophers regard as uncontroversially essential to basic moral principles. We can't have a basic moral principle that says "such-and-such is right for John Jones but wrong for everyone else." Can we have one that says, "such-and-such is right for people, but wrong for everyone else"? Recent writers on this matter have coined the ugly word, "speciesism," to stand for precisely such views. They wish to hold that "speciesism" is as untenable as racism, or John Jonesism. (Many of you will be unfamiliar with this unusual view on moral philosophy. It says, in brief, that everyone must do whatever John Jones says.) I think they are right about this, actually; but not, I think, in just the way they think. We shall return to this.

Now, consider this argument of Regan's: "If to cause suffering is wrong, then it is wrong no matter who is made to suffer" (129). Not many would disagree. Indeed, how could they? No doubt if suffering, just as such, is wrong, it follows logically that it is wrong (prima facie) in all cases. But is it thus wrong? Does suffering matter, just all by itself? Or does there have to be a reason why the sufferings of a given being matter? That is the question; and it is one which simple logic will not decide for us.

This brings us to the other criterion: conformity to our moral "intuitions." Once upon a time, philosophers were inclined to argue that we have a special "faculty" of moral truth, a little black box in the soul that tells you when something is right and when not. Regan doesn't buy this view, of course-it's easily shown to be untenable. Another thing he doesn't mean is that we can test moral principles just by asking any Tom, Dick, or Henrietta whether they happen to agree with them. When he talks about intuition, he means of course, reflective intuition, as appealed to by such eminent philosophers as Henry Sidgwick, W. D. Ross, and John Rawls. 
Nevertheless, there is an evident and classic objection to the use of intuition as a criterion of correctness in etbical theory: What do we do when intuitions conflict - when your considered intuition says that a certain kind of thing is wrong, mine that it is right? Regan has a reply to this, arguing that it "fails to recognize the difference between a principle's being valid for all and our knowing that it is," and he goes on to say that "When we have subjected an ethical principle to the tests of consistency, scope, precision, and conformity with our reflective intuitions, and when we have done this while making a conscientious effort to make an ideal moral judgment, we have done all we can reasonably be required to do to be in a position to justify that the principle is binding on all moral agents" (139-emphasis added). But this mistakes the issue, and indeed, sweeps it under a theoretical carpet. The problem is that if appeal to intuition is to be a test for the truth (= acceptability) of a proposed moral principle, then it is a test such that mutually contradictory proposed moral principles could each pass it. Such a test cannot, by definition, be sufficient. Once we allow that men of good will can both be wrong, we have as good as admitted that appeals to good will aren't enough, if what we are looking for is the truth.

The appeal to intuition, in short, is theoretically bankrupt. It cannot be a source of moral knowledge. Nor will it do to offer the pious hope that all men of good will would agree when they have gone through all the steps. For as long as an appeal to intuition is one of the admissible steps, there will be the same problem: The steps simply don't give us any good reason to expect agreement, for they offer us nothing to explain what we are agreeing or disagreeing about when we have moral arguments. So if people did agree, with sufficient use of intuition, it would have to be an accident, not a fact of theoretical significance.

We could partly solve problems of this kind by adopting a stance of tolerance and liberalism: You do it your way (in accordance with your intuition) and I'll do it mine (in accordance with my intuition). That, in fact, is part of the solution I recommend, and indeed substantially the solution currently accepted. But of course it is not a solution available to Regan, for in his view, my practice is urong. That is not compatible with saying, "to each his own." And indeed, as is evident from his concluding chapter, if Regan had his way about it, I would not even be legally allowed to do things my way (e.g., eating hamburgers). The liberal idea is itself, of course, a moral stance, and not, for instance, another component of a neutral idea of "moral reasoning." But in its application to the present subject, it is not a stance Regan can take.

But let us return to the exposition of Regan's basic argument. On the one hand, basic moral principles must be impartial, universal, general. That is the major premise. The minor premise is an observation about current intuitions. There are two important things which, he thinks, we all believe: (1) that human infants, feeble-mindeds, and other of what I have elsewhere called "marginal cases" bave rights, and (2) that they have those rights "in themselves" or inherently. 
The cases I have just mentioned belong to a class of what Regan calls "moral patients," a term needing some explanation. A moral agent is, of course, one which acts, and in particular acts (or at least can act) in the light of moral requirements and other moral considerations. A "moral patient," by contrast, is one which we can affect by our actions, for better or worse, but which cannot itself act in response to moral considerations at all. Such, of course, would be animals. And one way of putting the basic question of this controversy is this: What are our duties, if we have any at all, to moral patients? (And, of course, why?)

Now the view which, as I say, Regan attributes to all of us concerning some moral patients, (namely human ones) is that we do indeed have duties to them, and moreover to them "in themselves," or "inherently." The contrast would be with what Regan calls "indirect" duties. Regan discusses these views extensively in his book ${ }^{3}$, where they are characterized as holding that such duties are really owed to other beings, rather than to the animals, infants, etc., themselves.

Now as we will see, I do want to advocate a view of some such kind myself. But I am uncomfortable with this way of characterizing the distinction. Suppose that I have promised you that I will take care of your child if you die suddenly. You do so, and now here is the child on my hands. Do I not owe that child my love, concern, and attention, even though the reason I provide them is that I made a promise to you, rather than to it? (And even though I definitely do not think I have such a duty to all the other children in the world, or any of them for that matter?) The distinction, in other words, is really a distinction in the fundamental grounds of our duties rather than their objects, and it is somewhat misleading to characterize them in a way that invites confusion on this head.

We should also have a look at the distinction between "moral agents" and "moral patients," as Regan draws it. The former, as usual, are those who act and whose actions are liable for moral appraisal. The latter term, however, Regan defines in a narrower way: as referring to those who are patients and not agents. This is unfortunate, since all of us agents are capable of being affected for better or worse. I should like to put this by saying that we are both agents and patients. If we use the term "patient" in Regan's "exclusive" way, however, then we may have at least a terminological problem. For that may leave us bereft of suitable vocabulary for expressing what seems to me an important possibility: namely, that the passive aspects of agents may matter morally, even though they nevertheless matter only by virtue of belonging to agents - despite the fact that they are not those aspects of agents in virtue of which they are agents.

To explain this perhaps somewhat complicated idea a little more: Suppose that a certain moral agent-Sally, we'll call her-has, in her wisdom, taken out an insurance policy in virtue of which certain doctors and others have the duty to cater to her headaches. Now, headaches are passive conditions. Nevertheless, the reason why the doctors involved in this insurance plan have 
the duty to minister to Sally's headaches is that they've signed up for it with her insurance company. Those doctors would have the duty to cater to Sally even though it might not be true that those doctors had duties to other individuals who had headaches but no insurance. Nowadays, to be sure, many people do think that all doctors have a duty to fix all headaches, regardless. But even if that is true-which I doubt-it would remain that Sally's doctor has the duty to cater to ber headaches over and above any obligation that doctor might have to "patients" in general.

The point is that we must not let ourselves be steamroliered into the assumption that patients are to be catered to as such. The example just given shows how the duty to cater to a certain need or want, even though that is a patient's aspect of the person in question, may nevertheless be founded on some agent's aspect of that individual. Another interesting example has to do with our dealings with loved ones. Regan agrees that we have the duty to loved persons to prefer a greater harm to someone else over a lesser harm to them, on occasion. And of course we shouldn't confine it to harms: we surely are also morally justified in preferring the lesser good of loved ones to the greater good of others. Given Regan's universalistic proclivities, there is a problem of how this can be justified. Regan, dipping once again into his fairly deep satchel of intuitions, simply puts these down as "special considerations" (316-his italics). But putting something in italics is not equivalent to giving an account of it. The fact is that love relations, though obviously directed toward others, are relations of self-interest-very deep ones though those interests may be.It is important to you that you chose that man or that woman, as friend, lover, spouse; that you wanted to have that child; and so for many other such cases. All that is accomplished by preferring that loved one's lesser needs or wants to the greater needs or wants of some stranger is that your and their lives are better as a result-not, for all you know, better than that of the stranger (by hypothesis, the marginal improvements to the respective lives in question are supposed to favor the stranger in these cases). If moral relations are generated essentially by rational agents promoting their own well-considered, long-run interests, these cases make sense. On the Reganian dispensation, they have to be listed as "special cases," no more said.

This brings us to the central issue: What, if any, duties do we have to patients qua patients, and why? And here, I fear, Regan's meta-ethical proclivities work ill. In his discussion of "Direct Duty Views," Regan has gotten to the point where he feels justified in rejecting theories because they don't support bis intuitions about animal rights. Thus, for example, he rejects the "cruelty-kindness" view (i.e., that the reason we shouldn't inflict harm on animals is that to do so is to display a vice, cruelty) on the ground that "kindness is not something we owe to anybody, is not anyone's due" (199)i.e., because this position would not imply that animals have the right not to be treated in those ways! But of course those of us who don't think that animals do have rights and who have not been persuaded by his other arguments, are not going to be impressed at this. 
Nor, similarly, will we be impressed at his rejection of utilitarianism for similar reasons. His discussions of utilitarianism are of considerable interest in their own right, to be sure; and he is quite right to point out that utilitarianism does not provide a firm foundation for the things he is convinced of: vegetarianism, the almost complete prohibition on the use of animals for experimental purposes, and so on. But is this a reason for disavowing utilitarianism-or is it instead a reason for disavowing those particular Reganian intuitions?

Then Regan introduces his heaviest theoretical weapon, the notion of "inherent value" (Ch. 7, "Justice and Equality"). He denounces utilitarianism, among other theories, on the ground that in their view, individuals are "mere receptacles" of what has intrinsic value (viz., pleasure or pain, for instance). "They have no value of their own; what has value is what they contain..." (205). Opposed to this, we are told, is the idea that individuals are valuable in their own right; that they have "inherent value," this being a sort of value which is (1) incommensurate with other values, and in particular, (2) "not reducible to the intrinsic values of an individual's experiences" (235). Inherent value is a property such that possession of it can only be equal in that respect. It is not, apparently, capable of variation in degree. Any given thing either has it or doesn't. And if it does, it has (for instance) rights; if not, not. If we think of individuals as "receptacles" for what has value, then the idea is that "It's the cup, not just what goes into it, that is valuable."

One would like to have a clearer idea of just what this postulate is supposed to imply, and why. For instance: One might think, given this idea that it is the "cup, and not what goes into it," that is "valuable," this being a value grounding a sort of respect that is not commensurate with any other considerations of value, that, for instance, we should have an absolute duty not to commit suicide, since the person contemplating suicide does so merely because the life awaiting him or her looks intolerable-extremely painful, or boring, or whatever. These, however, are mere intrinsic values of contents, and presumably aren't supposed to be capable of overturning the treatment that is due an individual in virtue of that individual's "inherent value." Regan doesn't bring out this implication, and presumably doesn't think it follows. But if not, why not? We are not told.

Regan is obviously very taken with this notion, and we soon find him treating it rather as if it were a sort of fact about the individuals who, he thinks, possess it that they do so. Thus in searching for the ground of inherent value, we find him looking for the "relevant similarities" among the individuals who have this sort of value - rather than demonstrating to those of us whose moral intuitions don't seem to be quite up to the job of spotting this interesting property that we have overlooked it, or that we even need to keep an eye out for it!

Nevertheless, there is an argument here. Having laid down, or "noted" (as we should probably put it) that moral agents have inherent value, the question then is whether moral patients do. And Regan claims that "the attempt 
to restrict inherent value to moral agents is arbitrary" (239). The argument seems to be this:

1) Moral agents have inherent value,

2) it is in virtue of that value that we have the duty not to harm them,

3) but (some of) the harms we can do to them (and which are morally prohibited by [2]) are just like the harms we can do to animals, and

4) we have a direct duty not to inflict those harms on those animals.

Therefore,

5) those animais also have inherent value.

(My summary of his argument, 239-40.)

But the conclusion doesn't follow from its premises. There is no logical reason why the ground for prohibiting harm to individuals with inherent value couldn't be different from the grounds for prohibiting the same harm to other individuals who don't have it. The claim that it is "arbitrary" to do so is either another appeal to intuition, or, if meant as a stronger claim, is just false. Note again the case of the health-insured patient, Sally, to whom Dr. Crowne owes an operation, even though Sally's need for it is identical to that of Albert who, however, lacks the relevant insurance. It obviously can be the case that one person can have a right to the very same patientaffecting thing that another person, identical qua patient, does not have a right to. And there are various other possibilities. The point is that Regan's argument doesn't rule them out - even if we accepted his premises, which I do not.

Now, I am inclined to agree that we should reject the suggestion that it is the "intrinsic value of the experiences" of a given subject that constitute the whole and only relevant fundamental ground of treatment of that being. (Again, my case of the insurance policy will illustrate this well enough). But if we go on to ask why it should be plausible to make any such distinction, Regan's idea of "inherent value" doesn't help. For if we ask how we are to know whether a given organism bas this property or not, then the only answer is that it's a matter of perception. We don't need, and can hardly have, an argument for the "view" that grass is green. But then, from the fact that grass is green nothing seems to me to follow directly regarding what we should do about it. We would need, in addition to that information, some such information as that we like green things, or that being green promotes some other states of affairs that we value, before we can get any conclusions about action. Similarly, why should the fact that a certain being would feel pain if I were to perform action X constitute a reason why I should refrain from $X$ ? Now, is it obvious that the "fact" that it has "inherent value" should have that implication? It is, I think, not obvious unless its having "inherent value" is just another way of stating that implication; in which case, we are back to the original question: Why should the fact that it would hurt organism $\mathrm{X}$ constitute a good reason for me to refrain from hurting it? Here, then, we turn to positive theory. 


\section{The "Why" of Rights for Marginal Persons and Animals}

One important possibility in answer to my last question would be that I dislike pain - not only my own, but that of others. That would explain why I should refrain from inflicting it on them as well as on myself. But unfortunately, it seems that not everyone is constituted that way. And what do we say to those people? What Regan will say is clear enough: They are morally below par.

I don't expect that those people would be impressed by that answer. They'd like to know why it's wrong to inflict pain on other creatures, apart from the fact that Tom Regan and maybe some other people have a unique and apparently inexplicable intuition, that it is wrong, or the fact-if indeed it's a different fact! - that lots of other people, such as myself, have a considerable aversion to doing so. I take it that neither of those facts would be sufficient, in and of itself, to give these skeptics a reason for accepting that they morally ought to refrain from those practices.

Perhaps it will be asked why there needs to be a reason of the kind I am looking for: that is, one that would be acknowledged by the skeptics in question. For note that the right word is "would," and not "should," in any irreducible or, of course, any moral sense. That is: in coming on as I do, I am implying that if action $\mathrm{X}$ is morally wrong, then there has to be a reason from the point of view of everyone for accepting the claim that it is wrong. For a moral argument to be any good, it cannot merely preach to the converted, who in the present case are those who already accept the view that it is wrong to kill or inflict pain on animals, even if doing so serves our ends. If we say to them that they "should" acknowledge such a reason, then they will raise the question why they should do so. And if in saying that they should, the advocate of animal rights was merely reiterating his own view about animal rights, then his argument is a nonargument, an exercise in circular reasoning. It is for this reason that I think we must reject appeals to intuition in ethics: where they are really needed, they are useless and merely irritating.

It is satisfactory to show that these others "should" acknowledge a certain reason for accepting a moral principle if we mean, in so saying, one of the following two things: (1) that it would follow from other things that they already accept; or (2) that there is good reason to think that they would accept it if they would consider points (a-n), these being either demonstrable facts or items which, from what we know of their psychological makeups, would appeal to them. The proof of this latter pudding, of course, is in the eating: Show them $(a-n)$ and see what it does. In the absence of either of these two ways of establishing to a given individual, B, that B should accept some moral view, it seem to me that we have not succeeded in establishing that view with him.

This explication of individual reasons amounts, I should note, to the following: $\mathrm{A}$ has a reason for doing something, $\mathrm{X}$ (of for accepting some practical claim, some claim upon A to do X) if it would on the whole conduce to the 
realization of A's values that A do X. A's values are the things that A values, that A holds to be valuable, attaches value to. (A less fancy - or is it fancier? way of saying this is that it would "maximize A's utility.") Obviously I do not here mean by "values" A's moral values.

Now "he," in the preceding argument, refers to just anybody who doesn't already accept whatever moral principle we are trying to establish. This does raise a question just who "anybody" is here. For present purposes, I think, it is any member of the class of moral agents whose actions we think are properly subject to the principle being advocated. Let us call this group the relevant "moral community." We can then formulate my thesis about moral arguments as follows: That in order for an act X to be morally wrong, it has to be true that there is a reason for everyone in the relevant "moral community" to acknowledge its wrongness:a reason, that is, that would move that agent into action.

But this requires further explanation. For I do not think that we must show that every member of the community has sufficient reason, just like that, for refraining from doing X.It is not luminously clear to me, nor I think to most people,that we do always have sufficient reasons for refraining from doing $\mathrm{X}$ even when we agree that $\mathrm{X}$ is immoral. But this should not daunt us from insisting, nevertheless, that there must be good individually considered reasons for morality. What we need to look for good reasons for, namely, is the imposition of a uniformity of conduct on the community in question. This imposition is done in all the familiar ways: of criticism, especially, and of subtle rewards and punishments. And it is done by everyone, and done with respect to everyone. This, I think, is the essence of morality: It is a set of rules for everyone in the moral community in question, and to be imposed by everyone. We have a satisfactory rational moral rule when we can see how everyone in the community benefits from there being a rule of that kind, including those who might nevertheless consider themselves on occasion to be better off for disobeying that rule. The rationality of the rule may not prevent them from such disobedience. What it will do is to prevent them from having any sort of case against those who attempt to impose it.

Note that the set of individuals who are members of the community in question are the moral agents of that community. The thesis that an acceptable moral rule must also be acceptable, by way of being of benefit, to the non-agents in the community-infants, the very feeble-minded, and animals - is not part of the view I am arguing for.

"Why not?", it will be asked. The reason is fairly simple and straightforward, but pretty devastating to many views of morality. In order for morality to have a point, it must have point for any individual subject to it. Now, the set of organisms in my environment with whom I must deal in the course of life may be divided into two classes: those who are capable of engaging in voluntarily self-regulated behavior with respect to me, of a type that I can have some influence on, and those not thus capable. 
This distinction, I believe, is radical and fundamental. With regard to those in the latter category, transactions from me to them are in a fundamental sense one-way: I can decide what to do about them, but they can't react by making adjustments in their principles of conduct, for they have none. But with regard to those in the former class, things are very different. When dealing with such entities, it is a fact I ordinarily would not be able to ignore, and certainly not one I could afford to ignore, not only that my actions make a difference to their behavior, and vice versa, but also that both of us can take a view in advance of what we are up to and communicate with the other what those lines of conduct might be and how we are going to interact with each other. Moreover, each of us knows that actions of the other are capable of being beneficial or detrimental to us, and this matters to us. Put this all together, and we have a case - an individually considered case--for considering the establishment of the sort of mutual principles known as "moral" ones. Each of us would prefer that others perform actions that are beneficial to us, or at very least not detrimental. And each of us knows that the other may well have options beneficial to him or her that are detrimental to ourselves. Obviously we have an interest in seeing to it that others by and large choose their actions from the former class and not from the latter.

In order to do this, however, we must make it a good thing from their point of view to adopt this preference. How do we do that? In part by threatening the other with undesirable consequences if he or she doesn't adopt that preference, and partly by promising similar behavior on our own part. In short, we shall adopt principles of mutual advantage.

But with regard to animals and other non-agents, this procedure isn't available. In the first place, communication with them is not efficient or extensive enough to enable any such mutuality of principle to be adopted. And in the second, they may not have enough to offer us to make it a good deal from our point of view to modify our antecedent line of behavior with respect to them-which is, roughly, to do whatever seems to serve our advantage best, regardless of its effect on them. This, indeed, is our "antecedent line of behavior" with regard to everyone, I take it; but we learn rapidly enough that as a principle of conduct for dealing with like-minded other beings, it just won't do.

It's not obvious that it won't do for animals and the like, however. We would seem to require some reason for abandoning that tendency that can hardly be of the same kind as it is when we consider our relations with our fellow rational beings. In their case, there's no difficulty, for anyone of remotely normal psychology, in seeing the reasons for limiting our tendency to consider each other only as useful or useless in relation to our own ends. But there certainly is such difficulty in regard to animals and the like.

A bit more can and should be said about the "and the like" part of this last sentence. All of the members of this class, that I know of, anyway, are what I have elsewhere referred to as "marginal cases" of human beings - to put it somewhat misleadingly. There is no intention to derogate entities so 
described, I hasten to add. Some of the humans for whom I have the greatest affection are, or until recently were, members of that set. My relations with some of those members, in short, are determined by sentiment. Which does not mean that they are not determined by reason. Nothing can be more reasonable than taking care of and giving pleasure to those we love and who love us. The point about sentiment, though, is that as far as any particular other being is concerned, we may or may not have it toward that individual. And where we do not, it is no good saying we "should." Either we do or we don't, so far as sheer, native sentiment is concerned.

Now it happens, though, that humans all come from other humans and that in the normal course of events, those other humans do have such relations toward us, and we toward them - not invariably, to be sure, but normally, and indeed overwhelmingly often. In general, in other words, so far as any particular "marginal human" is concerned, we may be virtually certain that there are a few people who have a sentimental interest in the well-being of that individual. Nor is that all. For it is also true that we have, ordinarily, little if anything to gain by treating those individuals badly; whereas those who love them have much to lose if we do. If we turn from the special cases of paraplegics, imbeciles, and the like, to infants, there is a further and extremely important consideration: These are the organisms which will become full-fledged persons by and by. How we treat them now has a great influence on how they will treat us later on. It has a great influence on what the future community will be like, and that matters to us. The fact that they are not, as they stand, original members of the moral community means that it is up to us to decide what their status is to be; but the reason for giving them substantial rights is very strong indeed. It is also true enough, I think, that there is a general and positive sentiment toward fellow organisms of our species, as claimed by David Hume. It is not, I think, of sufficient strength to do the job Hume wanted it to do, but it is strong enough, when supplemented by the other point I have just been developing, to support the claim that there is a general public interest in having humans treat other humans well or at least not badly.

But if we turn to the various species of animals, things are different. We do not have much in the way of sentiment toward animals in general, for one thing. And, more important still, it is not true that for each animal there is some particular human who has a great interest in its welfare. Nor is it the case that for each particular human, there are particular animals in whom that human has an enormous interest, so as to generate a public interest in the well-being of animals in general. Whereas there is a great interest in animals which gives us strong incentive to kill them prior to the point in time at which they might have died anyway: viz., the interest in using them for food. This is not a vital interest, so far as I know. My information is that we could do without animal products in our diets and get on well enough, nutritionally. It is rather in the nature of an aesthetic interest: we like hamburgers, chicken a la king, swordfish steak, and so on and so on. And in the 
case of animal experimentation, we have interests of a major kind in the sort of information we can get from such experiments. Some of this information is certainly essential for the greater well-being of the human race, though a good deal of it is not.

Now if, as Peter Singer and most other enthusiasts for animal rights would have it, we had to justify these experiments or this slaughter by showing that our interest is greater than that of the animals who lose their lives or endure discomfort in the course of our pursuit of those interests, then it seems to me it would be game over, for the most part. From the point of view of the cow, I suppose, your and my interest in steak and the like may be pretty trivial compared to its interest in remaining alive. I may, no doubt, be giving too much benefit-of-doubt to the cow; I suspect that your typical cow doesn't really care all that much about its future, and indeed I am sure that your typical cow has essentially no notion of its future. But for the sake of argument, let us grant the cow more than the facts strictly support. My question remains: Well, so what?

What we have here, it seems to me, is a sort of "existential" question, if I read the existentialists rightly (and I take no responsibility for doing so!). As individuals, we simply have to make an ultimate choice: How much do we care about the cow? Or the pig? Or the swordfish? And so on for the rest of the animal kingdom. As for my part, I am quite clear about the answer: Not very much! Moreover, I am sure that is true for most people as well.

But if this is true, then there simply is no public interest that would support the view that animals literally have rights.I do not deny that they logically could have rights. If infants can have them, so can animals. But it is we who bestow these rights, and we must bestow them on the basis of considerations of collective interest. It is not enough that some few, or even quite a few people, are inclined to grant rights to all animals of various species. The rest of us are involved here, and we are not so inclined. Nor, I think, is this a matter of majority vote. Whether you or I have the right to life against people in general is not a matter of majority vote, and neither is the question of animal rights. It does seem to me that once a majority got overwhelmingly large on such a question, the view that there is a public interest in animals sufficient to support the granting of rights to them would become plausible. But nothing of that sort obtains at present in this society.

Can we even make a case against wanton cruelty to animals on the premises I am operating on? Here I am inclined to think that the overwhelming majority I refer to does exist. Nearly everyone sympathizes with the pains of other beings sufficiently to have an aversion against sheer sadism with respect to them, and against total and utter disregard of those feelings. This may in part, I think, be due to a suspicion of psychological transference as well: We find it hard to believe that someone who could utterly disregard the pains of any being in particular might not do likewise with regard to at least some humans, and the fundamental interest of all of us in not being the victim of any such persons is strong indeed. But I don't think this is a very strong consideration. 
On the whole, then, I see no good case for a general extension of rights to animals, at least at this level of generality. I do not rule out the possibility that some public-interest consideration might eventually be found. But I know of none at present. And until that time, I think we can eat meat and perform animal experimentation in good conscience.

\section{Endnotes}

${ }^{1}$ Paper presented at the national conference, "Animals and Humans: Ethical Perspectives," Moorhead State University, Moorhead, MN, April 21-23, 1986.

2 Professor, Dept. of Philosophy, University of Waterloo, Waterloo, Ontario, Canada N2L 3G1.

${ }^{3}$ Regan's discussion, unfortunately, is confined to the rather primitive exposition of my views found in my "Animal Rights" (Narveson 1977). A much better locus, I think, is the succeeding "Animal Rights Revisited" (Narveson 1980); as this was available to him at the time of writing, it is puzzling that he did not use it. I hope that the present effort will strike him as an improvement.

\section{References}

Narveson, J. 1977. Animal rights. Canadian J. Pbilosopby. 7(1): 161-78.

-. 1980. Animal rights revisited. Anim. Reg. Stud. 2. Amsterdam: Elsevier. pp. 223-36. Also published in: Miller, $\mathrm{H}$ and Williams, W. eds. Etbics and Animals. Clifton, NJ: Humana Press. pp. $45-60$.

Regan, T. 1983. The Case for Animal Rights. Berkeley, Los Angeles: Univ. of California Press. 